\title{
Investigando as Interações em um Ambiente Virtual de Aprendizagem por meio da Análise de Redes Sociais
}

\author{
Investigating Interactions in a Virtual Learning Environment through Social Network \\ Analysis
}

\author{
Helena Célia de Souza Sacerdote \\ Doutoranda em Ciência da Informação pela Universidade de Brasília - UnB \\ Professora da Faculdade de Tecnologia e Ciências Sociais Aplicadas do Centro Universitário de Brasília - \\ UniCEUB \\ E-mail: helenasacerdote@gmail.com
}

Jorge Henrique Cabral Fernandes Doutor em Ciência da Computação pela Universidade Federal de Pernambuco - UFPE. Professor do Departamento de Ciência da Computação do Instituto de Ciências Exatas da Universidade de Brasília - UnB. E-mail: jhcf@unb.br

\section{Resumo}

Este artigo analisa as interações entre os indivíduos participantes do Ambiente Virtual de Aprendizagem, utilizado como apoio às aulas presenciais de graduação, o Sistema Aprender da Universidade de Brasília. Analisa também o uso dos recursos disponibilizados no ambiente. A análise utilizou os dados das atividades dos usuários na troca de mensagens nos fóruns de discussões por meio do método exploratórios de Análise de Redes Sociais e utilizou também, os arquivos de registros de atividades individuais gerados pelo ambiente. Os resultados demonstram que as interações nos fóruns de discussão ocorreram somente entre os alunos, o que se atribui à modalidade de ensino. Os alunos mais centrais permaneceram nessa posição ao longo da disciplina. Houve similaridade nas interações dos indivíduos proeminentes. $\mathrm{O}$ uso dos recursos do ambiente pelos alunos mais proeminentes foi superior aos demais da turma, embora o aluno que mais utilizou os recursos não tenha sido o mais proeminente. O emprego da análise das interações e do uso de recursos no AVA como informações estratégicas para a avaliação de classes e indivíduos pode favorecer a projeto de ambientes adequados para o atendimento da necessidade do usuário no processo de ensino e aprendizagem em ambientes apoiados pelas tecnologias de informação e comunicação.

Palavras-chave: Interações Sociais. Ambiente Virtual de Aprendizagem. Análise de Redes Sociais.

\begin{abstract}
This paper analyzes the interactions between individuals in the Virtual Learning Environment, used as supporting college classroom, the Sistema Aprender of the University of Brasilia - Brazil. It also examines the use of resources available in the environment. The analysis utilized data from users' activities on the exchange of messages in discussion forums through the exploratory method of Social Network Analysis and used the files of individual activity logs generated by the environment. The results show that interactions in the discussion forums occurred only among students, which is attributed to the mode of teaching. Students remained in this more central position along the course. There was similarity in the interactions of prominent individuals. The use of environmental resources by students was more prominent than the others in the class, but the student who used the most resources has not been the most prominent. The use of analysis of interactions and resource use in AVA as strategic information for evaluating classes and individuals can promote the design of appropriate environments to meet the user's needs in the process of teaching and learning environments supported by information technology and communication.
\end{abstract}

Keywords: Social Interactions. Virtual Learning Environment. Social Network Analysis.

InCID: R. Ci. Inf. e Doc., Ribeirão Preto, v. 4, n. 1, p. 129-146, jan./jun. 2013. 


\section{Introdução}

Esse trabalho surgiu de um ensaio exploratório realizado para validar os instrumentos a serem utilizados na pesquisa de mestrado do Programa de Pós-Graduação em Ciência da Informação (PPGCINF) da Universidade de Brasília (UnB). O ensaio teve como objetivo responder aos seguintes questionamentos: É possível colher dados das interações sociais por meio dos arquivos de dados e de registros dos usuários gerados pelo sistema? Há condições de mensurar as interações sociais no Ambiente Virtual de Aprendizagem (AVA)? Há relevância das métricas de Análise de Redes Sociais (ARS) para a pesquisa?

O contexto do ensaio exploratório foi as interações entre indivíduos que ocorreram no AVA, por meio dos diálogos, troca de experiências e debates para fins de ensino e aprendizagem no Sistema Aprender da UnB. O objetivo foi verificar se as relações que ocorrem nesse ambiente mantêm o professor como principal mediador, fato comum na educação presencial. Além disso, buscou-se investigar o comportamento do usuário em relação ao uso dos recursos disponibilizados no ambiente para verificar se aqueles considerados proeminentes também são os que mais utilizam os recursos do ambiente.

As questões investigadas na pesquisa foram: Qual é a posição do professor durante as interações sociais para fins de ensino e aprendizagem no AVA? Como os indivíduos mais proeminentes utilizam os recursos disponibilizados no ambiente?

Um dos focos do estudo da Ciência da Informação (CI) é a comunicação da informação. Segundo Vickery e Vickery (1993), a essência do ato da comunicação é o conjunto das relações entre pessoas (relações sociais) que agem como, ou que estão associados a fontes, destinatários e canais de informação. Os elementos sociais que se comunicam podem ser indivíduos, grupos, organizações ou quaisquer outros componentes da sociedade. As principais funções da comunicação são: informar, instruir, comandar e influenciar. A comunicação informativa altera o estado do conhecimento do destinatário, sendo este um dos objetivos de toda a educação e instrução. De acordo com Valentim e Gelinsk (2005, p. 43), "construir conhecimento é uma atividade inerente ao ser humano".

Segundo Tomaél, Alcará e Di Chiara (2005, p. 96), “o espaço em que as redes sociais se constituem e se proliferam são inerentes à informação e ao conhecimento, uma vez que são eles que movimentam as redes".

InCID: R. Ci. Inf. e Doc., Ribeirão Preto, v. 4, n. 1, p. 129-146, jan./jun. 2013. 
$\mathrm{Na}$ aprendizagem formal ${ }^{1}$, o educador está no centro da mediação. Isso pressupõe que tal sujeito possui grande prestígio envolvendo o acesso, controle e a difusão da informação no ambiente que está inserido: "nos modelos pedagógicos convencionais, não existia um Outro diferente [...]. Quem existia era o 'detentor do saber', o sujeito epistêmico, sujeito/objeto ou o sujeito do construtivismo em sua dimensão consciente" (GOMEZ, 2004, p. 87). Com a inserção crescente das Tecnologias de Informação e Comunicação (TIC) em diversas áreas do conhecimento, inclusive na área da educação, e, com o uso de hipertextos e hipermídias, o papel do educador como detentor do saber e principal mediador da informação, pode também se transformar ao longo do processo de ensino e aprendizagem no AVA.

Quanto às interações entre sujeito e recursos, de acordo Moore e Kearsley (2008), são consideradas determinantes para a aquisição da aprendizagem e isso depende diretamente do indivíduo quando se insere no processo de aprendizagem. A autonomia do aluno acontece à medida que este determina os objetivos, as experiências de aprendizagem e as decisões de avaliação do programa de aprendizagem na relação de ensino e aprendizagem.

A metodologia utilizada foi a Análise de Redes Sociais (ARS) que tem sido utilizada de forma crescente pela Ciência da Informação. A ARS é uma metodologia de análise de dados relacionais que permite o estudo de fenômenos sociais. De acordo com Marteleto e Silva (2004, p. 48) "a análise de rede é uma alternativa metodológica que permite uma interlocução entre as ciências sociais e a ciência da informação, especialmente quando se leva em conta o conceito de capital social e o interesse que vem despertando nessas áreas".

A ARS permite identificar tendências ou padrões de comportamento ou a evolução das ligações entre os componentes da rede, pois o seu foco é o conjunto das relações que os indivíduos ou atores sociais estabelecem entre si, influenciando o desempenho de propriedades e funções dessa rede de relações. De acordo com Nooy, Mrvar e Baragelj (2005, p. 123, tradução nossa), "para a difusão e recuperação da informação, é crucial conhecer as pessoas que ocupam posições centrais na rede de comunicação”.

As interações sociais nesse estudo foram observadas por meio das métricas de centralidade em ARS. Os vértices (atores) mais importantes ou os mais proeminentes geralmente estão posicionados em locais estratégicos em uma rede. De acordo com Nooy,

\footnotetext{
${ }^{1}$ Aprendizagem formal: graduação, pós-graduação, seminários, workshops, cursos e todos os processos de educação continuada (ALVARES, 2010, p. 41).
}

InCID: R. Ci. Inf. e Doc., Ribeirão Preto, v. 4, n. 1, p. 129-146, jan./jun. 2013. 
Mrvar e Batagelj (2005), devido a sua posição, tais atores têm melhor acesso à informação e melhores oportunidades de disseminação das informações que circulam na rede.

\section{A Educação a Distância e as Interações no Ambiente Virtual de Aprendizagem}

A Educação a Distância (EaD) possui como características principais: o uso das TIC; o distanciamento espacial e temporal entre os alunos e professores, a conexão com a internet, os trabalhos colaborativos entre pares e o uso do AVA ou Sala de Aula Virtual. Para Moore e Kearsley (2008, p. 2) EaD é: “o aprendizado planejado que ocorre normalmente em um lugar diferente do local de ensino, exigindo técnicas especiais de criação de curso e de instrução, comunicação por meio de várias tecnologias e disposições organizacionais e administrativas especiais".

O AVA é um ambiente baseado em Internet, que funciona de forma semelhante a um Portal, cujo objetivo básico é a educação mediada pelas TICł. De acordo com Santos (2002, p. 426), um AVA é “[...] um espaço fecundo de significação onde seres humanos e objetos técnicos interagem potencializando assim, a construção de conhecimentos, logo a aprendizagem". AVAs têm sido utilizados também como apoio às aulas presenciais, como suporte tecnológico e, por meio de conexão com a Internet se constitui em um espaço de mediação para apropriação da informação.

Em um ambiente de interações, o papel central do mediador favorece um contexto de diálogo e de cooperação e esse papel é desempenhado pelo educador. $\mathrm{Na} \mathrm{EaD}$, a princípio, o educador tem mais proeminência e poder, porque atua como animador da inteligência coletiva (TARAPANOFF, SUAIDEN E OLIVEIRA, 2002).

De acordo com Almeida Junior (2008, p. 46), mediação da informação pode ser definida como: "[...] toda a ação de interferência - realizada pelo profissional da informação, direta ou indireta; consciente ou inconsciente; singular ou plural; individual ou coletiva; que propicia a apropriação de informação que satisfaça, plena ou parcialmente, uma necessidade informacional".

Para Gomes (2008, online), a mediação envolve: “[...] ambientes, ações, agentes, conteúdos, suportes, recursos tecnológicos, que se articulam na interseção entre a informação, a comunicação e a educação, cujo objetivo é o estabelecimento de estratégias a partir das quais se torna possível a geração de saberes”.

InCID: R. Ci. Inf. e Doc., Ribeirão Preto, v. 4, n. 1, p. 129-146, jan./jun. 2013. 
Oliveira (2003, online) entende que a mediação da informação é “[...] um processo de interface de: tecnologia, conteúdos e sujeitos sociais (usuários), na identificação e na satisfação das suas necessidades informacionais assim como na construção de conhecimento em um contexto socioeconômico e cultural determinado".

Segundo Masetto (2004, p. 145), a mediação pedagógica pode ser entendida como:

[...] a atitude, o comportamento do professor que se coloca como um facilitador, um incentivador ou motivador da aprendizagem, que se apresenta com a disposição de ser uma ponte entre o aprendiz e sua aprendizagem - não uma ponte estática, mas uma ponte "rolante", que ativamente colabora para que o aprendiz chegue aos seus objetivos.

De acordo com Masetto (2004), a mediação pedagógica envolve a interação, ou as relações, entre professor e aluno, entre aluno e aluno, entre aluno e conteúdo e até o aluno consigo mesmo. Envolvem diálogos, as trocas de experiências, debates para resolver dúvidas e problemas, reflexões, o estabelecimento de conexões entre o conhecimento e novos conceitos, o desenvolvimento do senso crítico, ético e colaborativo.

Segundo Masetto (2004), entre as características do professor mediador estão, o planejamento e as ações da aprendizagem centrados no aluno, a parceria e a coresponsabilidade no processo, a criatividade, o diálogo, entre outros, vez que ambos (professor e aluno) constituem-se a célula básica do desenvolvimento da aprendizagem.

Assim, a mediação pedagógica, de maneira semelhante à mediação da informação, pode ser considerada como o relacionamento entre: o conhecimento; o mediador e; o usuário da informação. Esses elementos se constituem em participantes ativos e colaborativos no processo de construção de novos saberes.

\section{Metodologia}

Para Wasserman e Faust (1994), a ARS surgiu no contexto das Ciências Humanas nos anos 30, incorporou formalismos da Teoria dos Grafos nos anos 60 e, a partir dos anos 70, passou a ser aplicada em diversas áreas do conhecimento. Os métodos da Análise de Redes Sociais começaram a ser investigados com maior rigor a partir da década de 40 e, possibilitam conferir elevado rigor matemático à análise estrutural nas Ciências Sociais.

Para Guimarães e Melo (2005), a ARS foi utilizada como instrumento para mapear os movimentos sociais, por favorecer a percepção das interações sociais e identificar o papel 
social do sujeito ou grupo em determinado contexto. Assim, por meio da ARS é possível identificar tendências ou padrões de comportamento ou a evolução das ligações entre os componentes de uma rede. O objeto de estudo da ARS é o conjunto das relações que indivíduos ou vértices sociais estabelecem entre si, influenciando o desempenho de propriedades e funções dessa rede de relações.

Alguns pesquisadores, tais como Nooy, Mrvar e Batagelj (2005) e Wasserman e Faust (1994) e Hanneman e Riddle (2005) produziram uma ampla descrição do conjunto de métodos de Análise de Redes Sociais.

De acordo com Hanneman e Riddle (2005), o poder é uma propriedade fundamental das estruturas sociais e está estreitamente ligado ao conceito de centralidade, além de ser inerente às relações sociais. Ter uma posição privilegiada significa que um ator pode ter maior influência entre os demais, ou seja, o ator será respeitado e terá a atenção daqueles em posições menos favorecidas.

A centralidade do ponto de vista da ARS pode ser definida como uma medida atribuída a pessoas ou organizações que reflete o nível de acesso à informação e às melhores oportunidades de intermediação e disseminação das informações, podendo inclusive, controlar a circulação das informações devido a sua posição dentro da rede. Atores com elevado grau de centralidade são capazes de efetuar trocas de informações significativas com os demais e também influenciá-los com os seus pontos de vista ou, se tornarem mais influentes na rede (WASSERMAN e FAUST, 1994).

As métricas utilizadas com o objetivo identificar as características de centralidade dos atores são: medidas de grau (degree), de proximidade (closeness) e de intermediação (betweenness). Tais medidas produzem índices que tentam mensurar a importância de um ator individual em uma rede.

De acordo com Nooy, Mrvar e Batagelj (2005), as medidas de centralidade são usadas em redes não dirigidas ou simétricas, que são os grafos simples. Um ator pode ser considerado central quando:

- Apresentar elevado grau;

- Se ele for facilmente acessível (perto) por todos os outros atores;

- Se ele encontra-se em vários geodésicos (caminhos mais curtos) entre outros atores.

InCID: R. Ci. Inf. e Doc., Ribeirão Preto, v. 4, n. 1, p. 129-146, jan./jun. 2013. 
Para Nooy, Mrvar e Batagelj (2005), o indicador mais simples de centralidade é o número de seus vizinhos, que é o seu grau em uma rede simples não dirigida. A centralidade de grau leva em consideração unicamente o grau do ator, sendo mais central aquele ator de maior grau, e fundamenta-se na hipótese de que quanto mais central é o indivíduo, mais facilmente a informação o atinge. Assim, quanto mais fontes a pessoa tem acesso (grau) mais fácil será obter informação. No entanto, o grau o ator por si só não nos informa se os atores de alto grau estão agrupados ou dispersos na rede, pois, essa medida apresenta apenas o seu número de vizinhos ou, o número de linhas que incidentes a ele (NOOY, MRVAR, BATAGELJ, 2005).

Outra medida de centralidade é a proximidade (closeness), que mede a distância total entre um ator e todos os demais. Segundo Hanneman e Riddle (2005), a medida centralidade de proximidade é baseada na soma das distâncias geodésicas a partir de cada ator em relação aos demais (distanciamento). Quanto mais próximo um ator estiver em relação a todos os outros na rede, as informações podem alcançá-lo mais facilmente e, maior será a sua centralidade. Isto porque tais atores podem ter formas alternativas para satisfazer as suas necessidades informacionais, pelo fato de possuírem mais acesso aos recursos e, portanto, são menos dependentes de outros indivíduos.

A centralidade de intermediação (betweenness) é a medida do número de vezes que um ator aparece no caminho geodésico entre dois atores. São aqueles que possuem vantagem posicional, ou poder, na medida em que eles possuem o caminho geodésico entre outros pares de atores. Como tais atores se colocam entre os demais, eles podem fazer o papel de intermediários ou mediadores. De acordo com Ugarte (2004), a intermediação nos dá uma aproximação do peso que um ator possui como conector ou mediador $(h u b)$ para que uma rede se mantenha unida. Para Recuero (2009) conector ou hub são os atores que possuem um número maior de conexões quando comparados aos demais em uma determinada rede. Eles são os principais propagadores e com maior potencial de atração de outros atores em uma rede. Com a retirada dos hubs uma rede pode ser desestruturada ou destruída.

A centralidade de intermediação se dá quando um elemento participa mais ativamente em um processo de interação. Quando um ator está no caminho de cada par de outros atores este tem a vantagem do poder de negociação porque para que ambos mantenham contato com outro, necessariamente têm que passar por ele. 
Os atores são os indivíduos que interagem no AVA ou, os usuários da informação, que nesse estudo, são alunos e professores.

A análise exploratória de redes sociais é composta por quatro atividades sequenciais e cíclicas que são: a definição da rede, a manipulação de redes, a determinação de características estruturais e, a inspeção visual (NOOY, MRVAR E BATAGELJ, 2005).

A definição da rede consiste na delimitação dos atores e suas relações.

A manipulação de uma rede consiste na seleção de sub-redes, ou, na extração de partes da rede que se mostrem significativas para uma análise mais apurada. Além disso, alguns procedimentos analíticos exigem que redes complexas sejam reduzidas a grafos simples (NOOY, MRVAR E BATAGELJ, 2005).

Segundo Nooy, Mrvar e Batagelj (2005), as características estruturais estão ligadas às métricas que serão utilizadas na pesquisa. Tais métricas podem ser relativas às redes do ponto de vista global, às sub-redes ou a atores individuais em relação às redes. Nessa pesquisa serão utilizadas: métrica global $\left(\mathrm{k}-\mathrm{Core}^{2}\right)$, para a identificação da formação dos subgrupos e; métricas de centralidade de atores individuais.

As visualizações facilitam intuitivamente os conceitos da rede. Uma das técnicas de visualização de rede é o sociograma. O Sociograma, originado da sociometria, é um instrumento de representação gráfica utilizada para revelar características sociais de atores em relação a um grupo (NOOY, MRVAR e BATAGELJ, 2005).

\subsection{Análise exploratória do AVA}

A metodologia empregada no estudo consistiu na obtenção de métricas de centralidade aplicadas à rede social, registrada por meio das atividades e interações dos usuários no AVA.

Também foram analisados os registros das ações dos usuários $\mathrm{n}$ ambiente, referentes ao uso dos recursos disponibilizados.

A pesquisa seguiu as seguintes fases: (i) análise da densidade da rede por meio da métrica k-núcleo; (ii) análise da posição dos indivíduos com mais ligações entre si por meio

\footnotetext{
${ }^{2}$ K-núcleo: Aglomerados de atores que indica os que estão ligados por k (mínimo grau de cada ator em um cluster) graus ou mais com outros atores dentro do cluster.
}

InCID: R. Ci. Inf. e Doc., Ribeirão Preto, v. 4, n. 1, p. 129-146, jan./jun. 2013. 
das métricas de centralidade e; (iii) análise das interações dos indivíduos mais centrais com os recursos disponibilizados no ambiente por meio do registro das ações individuais.

\subsection{Dados coletados}

Os dados de interações dos fóruns foram extraídos do arquivo backup ${ }^{3}$ do Moodle (Administração/Backup do curso/nomedadisciplina). Os dados de uso de recursos do AVA foram extraídos do relatório gerado pelo Moodle (nomedoparticipante/Relatório das atividades/Todos os acessos).

Os dados extraídos do backup foram transformados por meio do software utilizado para a ARS, o Pajek, para o formato .net, utilizando o seguinte pseudo-algoritmo:

- Se a mensagem é uma nova postagem então o usuário é inserido como um ator no ambiente;

- Se a mensagem é uma réplica a uma mensagem no fórum então o usuário é inserido como ator no ambiente e uma relação é registrada entre este usuário e o autor da mensagem que sofreu réplica.

Foram coletados dados referentes a dois momentos distintos: quando a turma estava em andamento, no mês de setembro de 2011 e após a conclusão da turma. No início da coleta de dados havia 37 usuários registrados no ambiente e no final existiam 44 usuários. Serão analisados os arquivos de $\log s^{4}$ dos usuários centrais para verificar a interação desses com os recursos disponibilizados no AVA.

\subsection{Análise dos dados}

\footnotetext{
${ }^{3}$ Cópia de segurança.

${ }^{4}$ Registro de ações dos usuários no AVA.

InCID: R. Ci. Inf. e Doc., Ribeirão Preto, v. 4, n. 1, p. 129-146, jan./jun. 2013.
} 


\subsubsection{Definição da rede}

O ambiente da pesquisa é o Sistema Aprender da UnB, ou simplesmente Aprender.UnB, um AVA baseado na tecnologia Moodle ${ }^{5}$, que permite o cadastro e gerenciamento de várias turmas de disciplinas presenciais e não presenciais realizadas junto aos diversos cursos de graduação, pós-graduação e extensão da Universidade de Brasília. O controle aplicado às turmas no Aprender.UnB é amplamente descentralizado, sendo o professor responsável pela criação de turmas, registro de alunos, design instrucional, entre outros. No caso nas turmas que utilizam o AVA como apoio a aulas presenciais, as atividades contam com a presença dos professores mediadores.

Os indivíduos considerados nesta pesquisa referem-se ao professor e aos alunos de cursos distintos de graduação da UnB que frequentaram a turma presencial da disciplina Informática \& Sociedade no $2^{\circ}$ semestre de 2011, especialmente alunos de computação, que ocorreu entre 17 de agosto e 14 de dezembro de 2011. A turma contava com 44 alunos regularmente matriculados e, o AVA foi utilizado como apoio à turma presencial.

As redes sociais analisadas foram geradas por meio do registro das atividades que os usuários realizaram na turma virtual cadastrada no AVA. O professor da disciplina é também um dos autores dessa pesquisa. Os indivíduos analisados foram identificados por números atribuídos pelo AVA Moodle.

\subsubsection{Manipulação da rede}

No caso desse estudo, foram identificados os subgrupos com mais interações entre os indivíduos. O pressuposto é que os indivíduos com muitas interações mútuas possuem um perfil significativo para a pesquisa.

Além da identificação dos subgrupos coesos (grupos com laços significativos), as redes serão reduzidas a grafos simples, que implica em excluir os seguintes dados de interação: loops (quando um ator envia uma réplica a uma mensagem de sua própria autoria), linhas múltiplas (quando um ator envia mais de uma mensagem para outro em um fórum de

\footnotetext{
${ }^{5}$ O Moodle é um Sistema Open Source de Gerenciamento de Cursos - Course Management System (CMS), também conhecido como Learning Management System (LMS) ou um Ambiente Virtual de Aprendizagem (AVA). (http://moodle.org/about/).
}

InCID: R. Ci. Inf. e Doc., Ribeirão Preto, v. 4, n. 1, p. 129-146, jan./jun. 2013. 
discussão) e direcionamento das linhas referentes às interações. Isso significa que não serão considerados se indivíduo enviou ou recebeu mensagens nos fóruns de discussão.

\subsubsection{A determinação de características estruturais das redes}

As características estruturais da rede referem-se às métricas utilizadas na pesquisa. Nessa pesquisa serão utilizadas: k-núcleo, centralidade de grau, centralidade de proximidade e centralidade de intermediação.

\subsubsection{Inspeção visual}

Os dados numéricos referentes aos registros de dados das interações entre os indivíduos no AVA do Sistema Aprender.UnB foram convertidos em métricas e visualizados no sociograma, conforme ilustrados na Figura 1 e na Figura 2.

Além das quatro fases de ARS, será analisado o uso dos recursos pelos indivíduos considerados mais proeminentes no AVA, que foram identificados por meio das métricas de centralidade, utilizando para isso o arquivo de $\log$ de cada inidivíduo.

\subsection{Resultados}

O professor da turma criou alguns fóruns, mas não interagiu com os alunos por meio deste recurso. As respostas aos questionamentos normalmente gerados por alunos ao longo da disciplina foram realizadas por meio de recursos externos ao ambiente, tais como e-mails e comunicação oral durante as aulas presenciais, uma vez que o AVA se constituiu um apoio às aulas. Assim, os indivíduos (atores) desse estudo representam apenas os alunos da turma.

A primeira fase da análise envolve a rede do ponto de vista global. Para isso, aplica-se a métrica k-núcleo (k-Core) que divide a rede em subgrupos de atores com mais ligações com outros na rede.

A primeira inspeção visual, da visão referente ao mês de setembro, mostra uma rede de 37 atores (Figura 1). Por padrão do software Pajek, as cores representam k-núcleos específicos. Os pontos na cor vermelha representam que, os indivíduos desse subgrupo 
efetuaram três interações entre si; os pontos na cor verde representam duas interações entre si e; os pontos na cor amarela representam uma interação ao longo da disciplina. Quando o ator envia uma mensagem e não obtém resposta, esse indivíduo é considerado isolado e, o ponto que o representa possui a cor azul claro. O ator circulado na cor azul escuro na Figura 1, representa aquele que efetuou mais interações ou, o mais central.

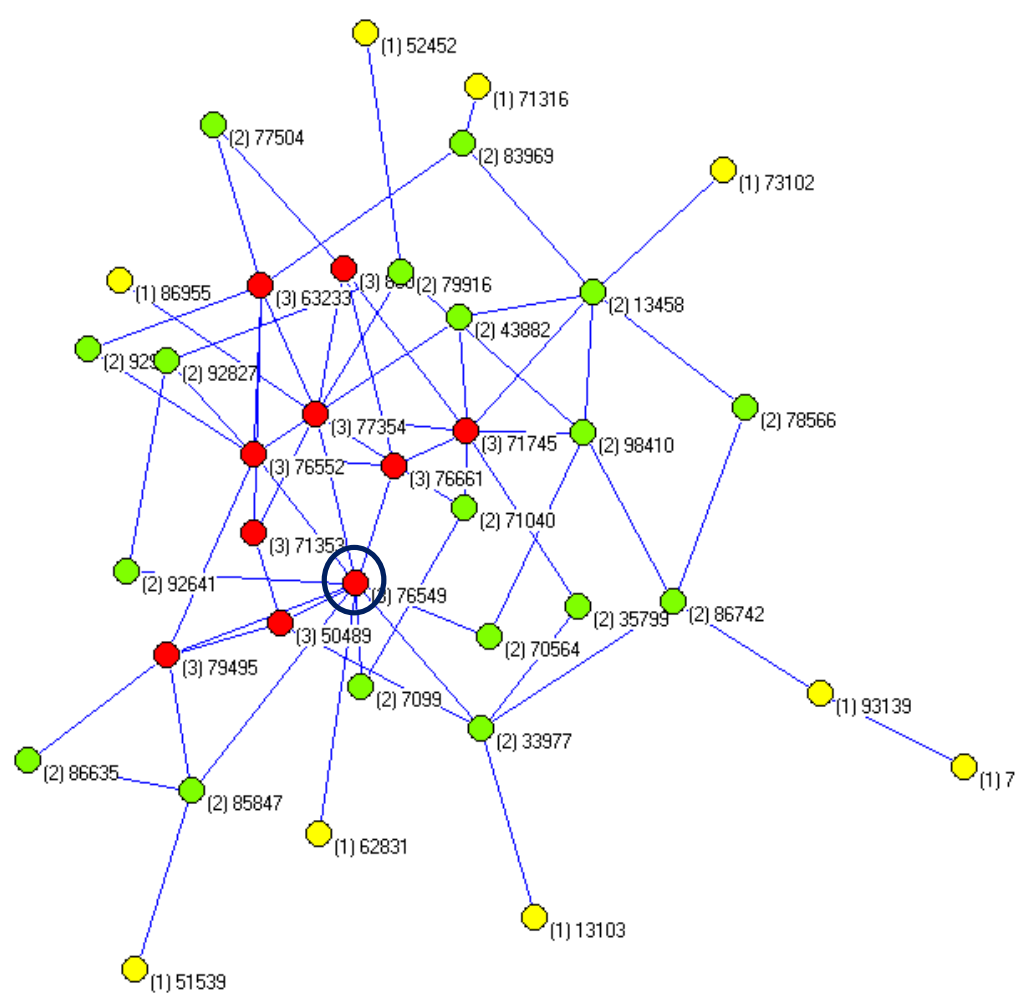

Figura 1 - Sociograma das trocas de mensagens nos fóruns da turma da disciplina Informática \& Sociedade $-2^{\circ} / 2011-1^{\mathrm{a}}$ visão

Fonte: os autores.

A segunda inspeção visual da visão (Figura 2) referente à disciplina concluída representa uma rede de 44 atores. Identificam-se nessa ocasião atores isolados. Isso indica que os dois atores 93553 e 93875 trocaram apenas mensagens entre si e não interagiram com mais nenhum outro na rede.

O subgrupo com três graus de ligação (3--núcleos) mostra uma sub-rede coesa com significativo aumento na coesão da rede quando comparada à primeira visão (Figura 1). 


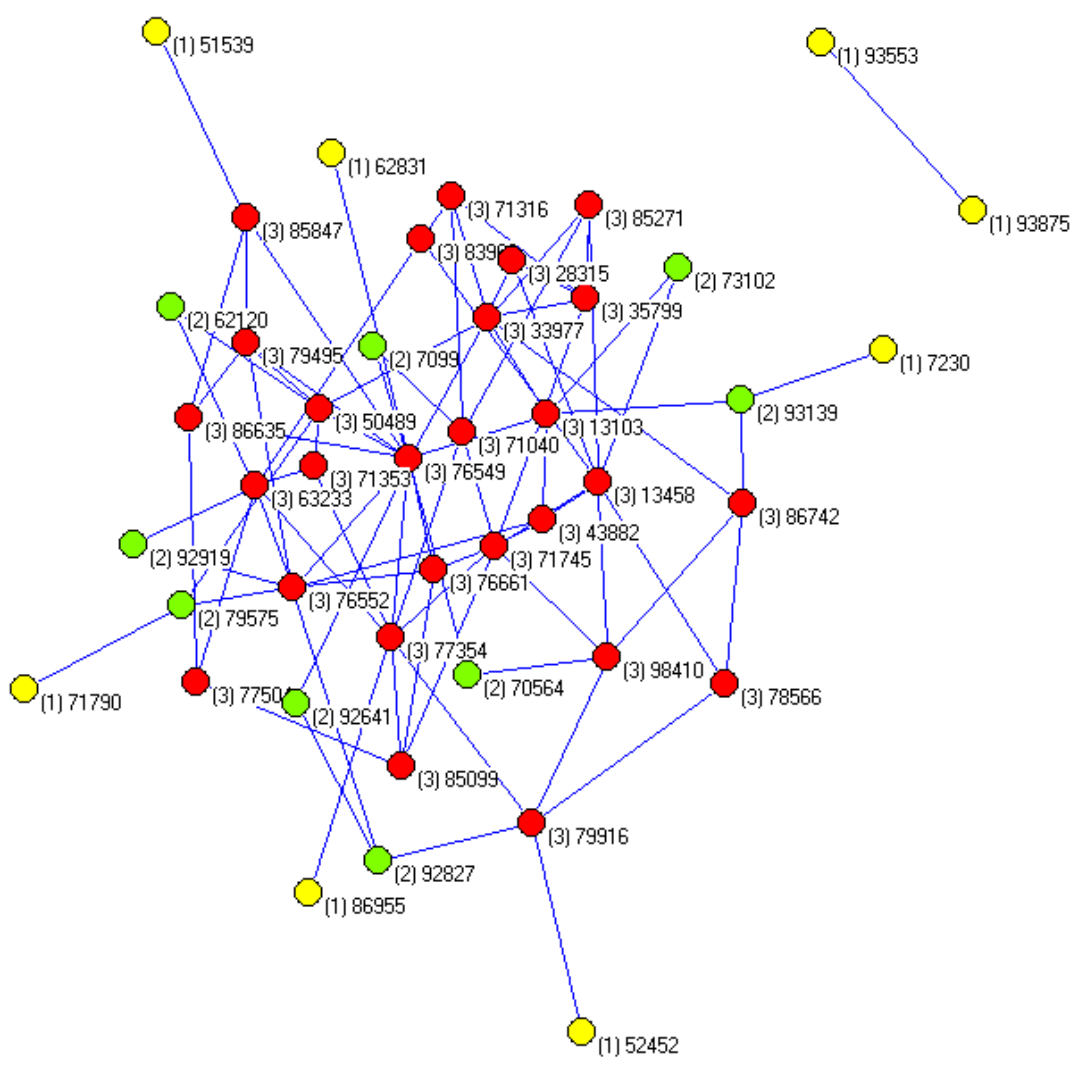

Figura 2 - Sociograma das trocas de mensagens nos fóruns da turma da disciplina Informática \& Sociedade $-2 \% 2011$ - disciplina encerrada Fonte: os autores.

Pela inspeção visual, observa-se o aumento de atores e de interações conforme a disciplina se desenvolveu. Também houve aumento da intensidade das interações (densidade da rede), uma vez que as interações com no mínimo três trocas de mensagens entre participantes, representados pelos pontos vermelhos, também aumentaram.

Para a próxima fase da análise, a centralidade individual de cada participante, foram selecionados os atores que se mantiveram no núcleo máximo de interações no início e no final da disciplina, momentos em que se obteve cada visão do ambiente, conforme ilustrado no Quadro 1. 
Quadro 1 - Medidas dos alunos que trocaram pelo menos três mensagens entre si nos fóruns de discussão ao longo da disciplina

\begin{tabular}{|c|r|r|r|r|c|c|c|c|}
\cline { 2 - 9 } \multicolumn{1}{c|}{} & \multicolumn{2}{c|}{ Núcleo } & \multicolumn{2}{c|}{ Grau } & \multicolumn{2}{c|}{ Proximidade } & \multicolumn{2}{c|}{ Intermediação } \\
\cline { 2 - 9 } \multicolumn{1}{r|}{} & Set & Final & Set & Final & Set & Final & Set & Final \\
\hline 76549 & 3 & 3 & 11 & 13 & 0,4931507 & 0,5218182 & 0,3426512 & 0,3112827 \\
\hline 77354 & 3 & 3 & 8 & 8 & 0,4736842 & 0,4253953 & 0,1930008 & 0,0687631 \\
\hline 71745 & 3 & 3 & 8 & 8 & 0,4444444 & 0,4659091 & 0,1370578 & 0,1457620 \\
\hline 76552 & 3 & 3 & 7 & 8 & 0,4444444 & 0,4550740 & 0,1408409 & 0,1293345 \\
\hline 63233 & 3 & 3 & 6 & 7 & 0,3956044 & 0,3953168 & 0,1082332 & 0,0710243 \\
\hline 79495 & 3 & 3 & 5 & 5 & 0,3913043 & 0,3657604 & 0,0554233 & 0,0253177 \\
\hline 76661 & 3 & 3 & 4 & 4 & 0,4137931 & 0,3557851 & 0,0276209 & 0,0442968 \\
\hline 50489 & 3 & 3 & 4 & 6 & 0,3870968 & 0,4076705 & 0,0307596 & 0,0761219 \\
\hline 85099 & 3 & 3 & 4 & 4 & 0,3750000 & 0,3623737 & 0,0274679 & 0,0130258 \\
\hline 71353 & 3 & 3 & 3 & 3 & 0,3750000 & 0,3106061 & 0,0154686 & 0,0458103 \\
\hline
\end{tabular}

Fonte: os autores.

Notadamente o ator 76549 se manteve como o mais central em todas as métricas nas duas visões da disciplina onde os maiores valores são marcados na cor amarela, conforme ilustrado no Quadro 2. Nas métricas de grau e proximidade, esse aluno cresceu em sua proeminência. No entanto, na métrica de intermediação, o aluno apresentou queda. Os alunos 77354 e 76552 mantiveram a mesma medida de grau e, nas métricas de proximidade e intermediação apresentaram queda. O aluno 71745 foi o único que apresentou evolução em todas as métricas. $\mathrm{O}$ aluno 76552 foi aquele que apresentou os menores valores em todas as métricas utilizadas na pesquisa entre os quatro alunos mais centrais.

Quadro 2 - Alunos considerados mais centrais de acordo com as métricas de centralidade ao longo da disciplina

\begin{tabular}{|c|r|r|r|r|c|c|c|c|}
\cline { 2 - 9 } \multicolumn{1}{c|}{} & \multicolumn{2}{c|}{ Núcleo } & \multicolumn{2}{c|}{ Grau } & \multicolumn{2}{c|}{ Proximidade } & \multicolumn{2}{c|}{ Intermediação } \\
\cline { 2 - 9 } \multicolumn{1}{c|}{} & Set & Final & Set & Final & Set & Final & Set & Final \\
\hline 76549 & 3 & 3 & 11 & 13 & 0,4931507 & 0,5218182 & 0,3426512 & 0,3112827 \\
\hline 77354 & 3 & 3 & 8 & 8 & 0,4736842 & 0,4253953 & 0,1930008 & 0,0687631 \\
\hline 71745 & 3 & 3 & 8 & 8 & 0,4444444 & 0,4659091 & 0,1370578 & 0,1457620 \\
\hline 76552 & 3 & 3 & 7 & 8 & 0,4444444 & 0,4550740 & 0,1408409 & 0,1293345 \\
\hline
\end{tabular}

Fonte: os autores.

Identificados os atores mais influentes ou centrais, seguiu-se para a última fase, a análise do arquivo de $\log s$ de cada participante para verificar a interação destes com os recursos do AVA. A partir da análise do log, percebeu-se que em ordem de prioridade, o ator 76552 apresentou interação com o ambiente quase duas vezes maior quando comparado aos 
outros atores centrais, de forma geral. O único recurso que esse aluno não obteve o maior valor foi com o Questionário, conforme ilustrado no Quadro 3 e no Gráfico 1. No entanto, esse aluno foi o que apresentou os menores valores em todas as métricas das fases anteriores.

Quadro 3 - Uso dos recursos do AVA pelos atores mais centrais da turma

\begin{tabular}{|l|r|r|r|r|}
\hline & $\mathbf{7 6 5 4 9}$ & $\mathbf{7 7 3 5 4}$ & $\mathbf{7 1 7 4 5}$ & $\mathbf{7 6 5 5 2}$ \\
\hline Acesso ao Ambiente & 98 & 61 & 55 & 300 \\
\hline Interações nos Fóruns & 234 & 236 & 107 & 354 \\
\hline Questionário & 38 & 22 & 16 & 22 \\
\hline Acesso ao Material de apoio & 13 & 28 & 23 & 67 \\
\hline Acesso aos Perfis & 21 & 4 & 2 & 46 \\
\hline Glossário & & & & 2 \\
\hline Total & 404 & 351 & 203 & 791 \\
\hline
\end{tabular}

Fonte: os autores.

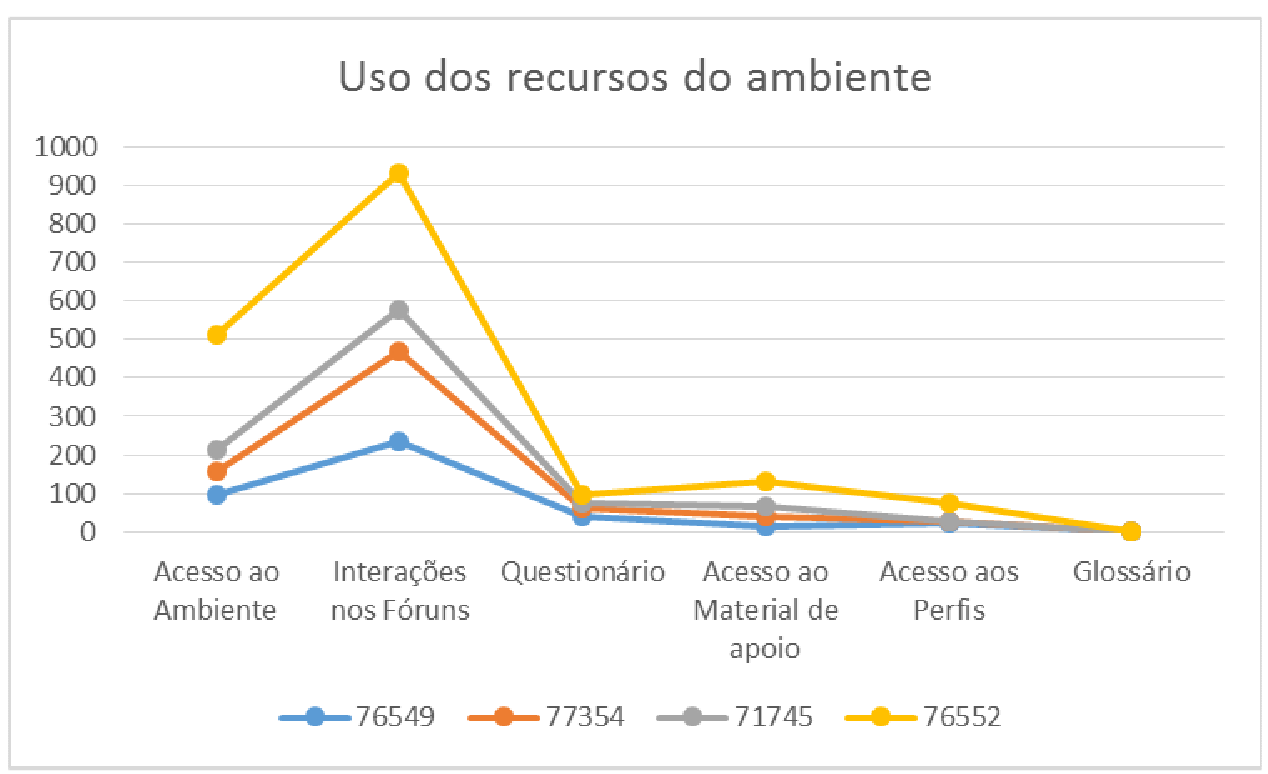

Gráfico 1 - Uso dos recursos do AVA pelos atores mais centrais da turma Fonte: os autores.

\subsection{Discussão dos resultados}

Do ponto de vista da densidade da rede em ARS, percebeu-se que a turma apresentou interações significativas e espontâneas, dado o fato de que os fóruns não eram obrigatórios e/ou avaliativos. Além disso, o grau de densidade evoluiu, o que se entende que a motivação para a discussão e troca de mensagens nos fóruns se manteve ao longo da disciplina. 
Do ponto de vista da centralidade, percebeu-se que os alunos centrais se mantiveram na mesma posição, com discretas variações, o que confirma o resultado da fase anterior.

Do ponto de vista do uso dos recursos do ambiente, percebeu-se que a maior interação dos quatro alunos na fase de análise do uso dos recursos se deu nos fóruns de discussão. Apesar do ator 76549 ter sido o mais central, quando se leva em conta os aspectos de centralidade analisados, o ator 76552 teve participação 95,79\% maior em relação ao ator mais central. Percebeu-se que o aluno 76552 é o mais ativo quanto: ao acesso ao ambiente, ao acesso às tarefas e também na interação com outros alunos. Também foi o único a interagir com o recurso Glossário. Na análise qualitativa dos $\log s$, observou-se que tal aluno acessou o perfil da maioria dos colegas e também o perfil do professor. Esse aluno apresentou número elevado de visualização dos fóruns, o que indica interesse pelo assunto em pauta, mesmo que não tenha participado com a mesma intensidade no que diz respeito à troca de mensagens. Esse comportamento indica interesse de socialização com os demais, portanto, provavelmente um aluno com pouca experiência com ferramentas tecnológicas de apoio à educação.

Dessa forma, infere-se que nem sempre o mais central no que se refere à troca de mensagens nos fóruns de discussões, também é o que mais utiliza os recursos do ambiente. Os potenciais alunos mediadores podem ser incentivados pelos educadores para que possam trazer significativas contribuições na construção do conhecimento coletivo no AVA.

\section{Conclusões}

Conclui-se que é possível colher dados das interações sociais por meio dos arquivos de dados e de registros dos usuários gerados pelo sistema. As interações no AVA podem ser mensuradas e, essa análise possibilita avaliar as ações dos usuários relativas a trocas de mensagens e uso de recursos disponibilizados no ambiente.

Sendo o objetivo desse estudo, analisar as interações no AVA Aprender.UnB para verificar se as interações no ambiente são caracterizadas pela centralização do professor na mediação, observou-se que as interações e a mediação se deu apenas entre alunos. Levando em conta que a turma estudada utilizou o AVA como um apoio às aulas presenciais, percebese que tal peculiaridade contribuiu para a descentralização do professor dessa turma no Sistema Aprender. UnB. Assim, percebe-se que no caso estudado, o uso das TIC favorece a mediação entre os pares, mesmo sem a presença (mesmo que apenas virtual) do professor.

InCID: R. Ci. Inf. e Doc., Ribeirão Preto, v. 4, n. 1, p. 129-146, jan./jun. 2013. 
Quanto à transformação na centralidade dos mediadores e o papel que os atores desempenham ao processo de ensino e aprendizagem no AVA, percebeu-se similaridade no comportamento entre os atores mais centrais, pois permaneceram nessa posição ao longo da disciplina, embora houvesse discreta variação nos índices. Ao analisar o comportamento dos atores mais centrais em relação ao AVA para identificar se os mais influentes também são os que mais se utilizam dos recursos que o ambiente disponibiliza percebeu-se que isso pode não ser uma regra, uma vez que o uso dos recursos do ambiente pelo quarto dos quatro atores mais centrais foi muito superior ao do primeiro colocado.

O emprego da análise das interações e do uso de recursos no AVA como informações estratégicas para a avaliação de classes e indivíduos pode favorecer a projeto de ambientes adequados para o atendimento da necessidade do usuário no processo de ensino e aprendizagem em ambientes apoiados pelas TIC.

\section{Referências}

ALMEIDA JUNIOR, O. F. Mediação da informação: ampliando o conceito de disseminação. In: VALENTIM, Marta Lígia Pomim. Gestão da informação e do conhecimento no âmbito da Ciência da Informação. São Paulo: Polis: Cultura Acadêmica, 2008. p. 41-54.

ALVARES, L. M. A. R. Telecentros de informação e negócios como veículo de educação corporativa nas microempresas e empresas de pequeno porte. $2010.247 \mathrm{f}$. Tese (Doutorado)- Faculdade de Economia, Administração, Contabilidade e Ciência da Informação e Documentação, Universidade de Brasília, Brasília, 2010. Disponível em: <http://repositorio.bce.unb.br/handle/10482/7472>. Acesso em: 10 dez. 2012.

GOMES, H. F. A mediação da informação, comunicação e educação na construção do conhecimento. DataGramaZero: Revista de Ciência da Informação, v. 9, n. 1, fev. 2008.

GOMEZ, M. V. Educação em rede: uma visão emancipadora. São Paulo: Cortez: Instituto Paulo Freire, 2004.

GUIMARÃES, F. J. Z.; MELO, E. S. Diagnóstico utilizando análise de redes sociais. 2005. Projeto Final (Especialização em Engenharia de Produção)-COPPE/UFRJ, Rio de Janeiro, 2005.

HANNEMAN, R. A.; RIDDLE, M. Introduction to social network methods. Riverside: University of California, 2005. Disponível em: $<$ http://faculty.ucr.edu/ hanneman/ $>$. Acesso em: 30 set. 2011. 
MARTELETO, R. M.; SILVA, A. B. O. Redes e capital social: o enfoque da informação para o desenvolvimento local. Ciência da Informação, Brasília, v. 33, n. 3, p. 41-49, set./dez. 2004.

MASETTO, M. T. Mediação pedagógica e tecnologias de informação e comunicação. In: MORAN, J. M. (Org.). Novas tecnologias e mediação pedagógica. 8. ed. Campinas: Papirus, 2004.

MOORE, M. G.; KEARSLEY, G. Educação a distância: uma visão integrada. São Paulo: Cengage Learning, 2008.

NOOY, W.; MRVAR, A.; BATAGELJ, V. Exploratory network analysis with Pajek. Cambridge University Press, 2005.

OLIVEIRA, C. L. Escola digital integrada. Brasília, 2003. Disponível em:

$<$ http://www.sct.embrapa.br/enedi1/CeciliaLeite/IIENEDI.ppt >. Acesso em: 10 jun. 2011.

RECUERO, R. Redes sociais na internet. Porto Alegre: Sulina, 2009. 191 p. (Coleção Cibercultura)

SANTOS. E. O. Ambientes virtuais de aprendizagem: por autorias livres, plurais e gratuitas. Revista da FAEEBA - Educação e Contemporaneidade, Salvador, v. 11, n. 18, p. 425-435, jul./dez. 2002. Disponível em:

<http://www.uneb.br/revistadafaeeba/files/2011/05/numero18.pdf > . Acesso em: 10 fev. 2012

TARAPANOFF, K.; SUAIDEN, E.; OLIVEIRA, C. L. Funções sociais e oportunidades para profissionais da informação. DataGramaZero: Revista de Ciência da Informação, ano 3, n. $5,2002$.

TOMAÉL, M. I.; ALCARÁ, A. R.; DI CHIARA, I. G. Das redes à inovação. Ciência da Informação, Brasília, v. 34, n. 2, p. 93-104, maio/ago. 2005. Disponível em: $<$ http://revista.ibict.br/ciinf/index.php/ciinf/article/view/642/566 > . Acesso em: 10 fev. 2012.

UGARTE, D. Analizando redes sociales. 2004. Disponível em: <http://bitacora.lasindias.com/analizando-redes-sociales-i/>. Acesso em: 01 jun. 2012.

VALENTIM, M. L. P.; GELINSKI, J. V. V. Gestão do conhecimento como parte do processo de inteligência competitiva organizacional. Informação \& Sociedade, João Pessoa, v. 2, n. 15, p. 41-59, jul. 2005. Disponível em: <http://www.ies.ufpb.br/ojs2/index.php/ies/article/view/31>. Acesso em: $11 \mathrm{dez} .2012$.

WASSERMAN, S.; FAUST, K. Social network analysis: methods and applications. Cambridge: Cambridge University Press, 1994. 857 p.

VICKERY, B.; VICKERY, A. Information science in theory and practice. London: Bowker-Saur, 1993. 